\title{
Studies on Prevotella nuclease using a system for the controlled expression of cloned genes in P. bryantii TC1-1
}

\author{
Tomaž Accetto and Gorazd Avguštin
}

Correspondence

Gorazd Avguštin

gorazd.avgustin@bfro.uni-lj.si

Received 10 January 2007

Revised 26 March 2007

Accepted 28 March 2007

\author{
University of Ljubljana, Biotechnical Faculty, Zootechnical Department, Chair for Microbiology \\ and Microbial Biotechnology, 1230 Domžale, Slovenia
}

\section{INTRODUCTION}

Members of the bacterial genus Prevotella have been found in the rumen as well as in the oral cavity and large intestine of man and animals (Edwards et al., 2004; Paster et al., 2001; Duncan et al., 2003; Eckburg et al., 2005; Leser et al., 2002). In the rumen they are symbionts contributing to the degradation of plant cell-wall polysaccharides (Miyazaki et al., 2003) and protein metabolism (Walker et al., 2003), whereas oral prevotellas are implicated in dental plaque establishment (Kolenbrander et al., 2002), periodontitis (Paster et al., 2001), advanced caries (Martin et al., 2002), oro-pharyngeal abscesses (Brook, 2004) and noma, a grotesque childhood orofacial gangrene, now confined mostly to sub-Saharan Africa (Enwonwu et al., 2006). The genetic tools that would make possible more thorough studies of prevotellas are still undeveloped despite their ecological and medical importance. This appears to be primarily due to the large phylogenetic distance between prevotellas and other well-characterized micro-organisms, and as a consequence of the rather specific genetic elements, exemplified by promoters, containing distinct $-7 /-33$ consensus sequences that are recognized by unusual primary $\sigma$ factor (Vingadassalom et al., 2005). Nevertheless, in two studies (Shoemaker et al., 1991; Accetto et al., 2005) the plasmid replicons and tetQ selectable marker derived from Prevotella and related colonic Bacteroides strains were used successfully for shuttle-vector introduction into the xylan-degrading ruminal species Prevotella bryantii, which forms a distinct phylogenetic lineage apparently somewhat closer to oral

The GenBank/EMBL/DDBJ accession numbers for the $P$. bryantii $\mathrm{B}_{1} 4$ and TC1-1 nucB sequences are EF472956 and EF472957, respectively. prevotellas than the other ruminal Prevotella species (Avguštin et al., 2001). Based on the conjugal transfer protocol developed in the first study, a $P$. bryantii $\mathrm{B}_{1} 4$ carboxymethylcellulase gene, fused to a cellulose-binding domain of Thermomonospora fusca cellulase, and driven by a Prevotella ruminicola 23 xylanase promoter, was introduced into $P$. bryantii $\mathrm{B}_{1} 4$. The gene was expressed in Bacteroides uniformis 1108, but not in $P$. bryantii $\mathrm{B}_{1} 4$, possibly due to $P$. bryantii $\mathrm{B}_{1} 4$ not recognizing the $P$. ruminicola 23 xylanase promoter (Gardner et al., 1996). In the second study, a shuttle vector pRH3, constructed on the basis of Prevotella sp. 223/M2/7 plasmid pRRI2 (Daniel et al., 1995), and protected against restriction, was successfully transferred to $P$. bryantii TC1-1 by electroporation (Accetto et al., 2005). These studies highlighted, among other factors, the importance of enzymic barriers preventing the successful establishment of foreign DNA in the microbial cell. Besides restriction enzymes, non-specific nucleases may be involved too, as in the case of Vibrio cholerae and Vibrio vulnificus, where representatives of these mostly extracellular enzymes having no sequence and sugar specificity (Rangarajan \& Shankar, 2001; JarvillTaylor et al., 1999) have been shown to inhibit transformation (Focareta \& Manning, 1991; Wu et al., 2001). Besides inhibiting transformation, they have been ascribed various roles in nutrition (Benedik \& Strych, 1998), in the processing of DNA during natural transformation, e.g. in Bacillus subtilis and Streptococcus pneumoniae (Provvedi et al., 2001; Dubnau 1999), and in virulence (Bendjennat et al., 1999). Most P. bryantii strains have high nucleolytic activity (Avguštin et al., 1997) and strain $B_{1} 4$ was shown to posess a $45 \mathrm{kDa}$ non-specific nuclease (Accetto \& Avguštin 2001). The electrotransformation frequency of $P$. bryantii 
TC1-1 with pRH3 (Accetto et al., 2005) could thus be risen considerably if the non-specific nuclease genes in the recipient strain were inactivated. We report here on the cloning of a $P$. bryantii $\mathrm{B}_{1} 4$ non-specific nuclease gene named $n u c B$ and an attempt to express it in its native background.

\section{METHODS}

Bacterial strains, plasmids, primers, media and growth conditions. The P. bryantii strains $\mathrm{B}_{1} 4$ (the type strain) (Bryant et al., 1958) and TC1-1 (Van Gylswyk, 1990) were grown anaerobically at $37^{\circ} \mathrm{C}$ in rumen fluid containing M2 medium (Hobson, 1969) or DSMZ medium M330, which was slightly modified: $\mathrm{Na}_{2} \mathrm{~S}$ and glycerol were omitted, $1 \mathrm{~g} \mathrm{l}^{-1}$ each of maltose, cellobiose and soluble starch were added, and the glucose content was increased from $0.5 \mathrm{~g} \mathrm{l}^{-1}$ to $2 \mathrm{~g} \mathrm{l}^{-1}$. When needed, tetracycline was added to the medium at the final concentration of $2.5 \mu \mathrm{g} \mathrm{ml}^{-1}$ prior to inoculation. Escherichia coli TOP10 was obtained from Invitrogen and was grown on LB medium at $37{ }^{\circ} \mathrm{C}$ with the appropriate antibiotics. The shuttle vector pRH3 (Daniel et al., 1995) was kindly donated by Harry J. Flint (Rowett Research Institute, Aberdeen, Scotland). The cloning vector pUC19 was obtained from Promega. The oligonucleotide primers used in the study were synthesized at Microsynth at our request, and are shown in Table 1.

Preparation of cell-free extracts. Cells were broken with a beadbeater apparatus (BioSpec Products), the DNA was removed with streptomycin (Accetto et al., 2005), and the resulting extracts were used for determination of nuclease activity by means of the quick nuclease assay or DNA protection as described previously (Accetto et al., 2005).

Preparation of cell-wash extracts. The cells were washed once in $\mathrm{TE}$, and then resuspended in one-tenth of the original volume in $10 \mathrm{mM}$ Tris $\mathrm{pH} 7.5,100 \mathrm{mM} \mathrm{NaCl}, 0.1 \%(\mathrm{v} / \mathrm{v})$ Triton X-100, as described by Takahashi et al. (1996). After centrifuging, the cell-wash extracts were collected and, if necessary, concentrated using Microcon YM-10 centrifugal filter devices (Millipore).
Quick nuclease assay. Seventeen microlitres of cell extracts or culture supernatants were mixed with $2 \mu \mathrm{l}$ of $0.25 \mu \mathrm{gl}^{-1} \lambda$ or plasmid DNA and $1 \mu \mathrm{l}$ of $10 \times$ restriction enzyme buffer A from Roche, and incubated at $37^{\circ} \mathrm{C}$ for $1 \mathrm{~h}$. The proteins were then removed with phenol, and the samples were analysed by means of standard DNA gel electrophoresis.

Sequencing. The sequencing of plasmid and PCR DNA, as well as the direct sequencing of genomic DNA, was performed on request by Microsynth.

Bioinformatic tools. For computer-assisted DNA analysis we used BLAST (Altschul et al., 1997) at NCBI, PFAM search (Bateman et al., 2004) and SignalP signal peptide prediction (Bendtsen et al., 2004).

PCR. The following standard PCR reagent concentrations were used: $0.1 \mu \mathrm{M}$ primers, $2 \mathrm{mM} \mathrm{MgCl}_{2}, 0.2 \mathrm{mM}$ dNTPs and $0.5 \mathrm{U}$ Taq polymerase (Fermentas), in $20 \mu \mathrm{l}$ reactions. When amplified DNA was used for expression or when performing inverse PCR, the highfidelity PCR enzyme mix from Fermentas was used, and the reactions were set up according to the manufacturer's instructions.

Cloning of nucB. Sequence analysis of the previously cloned chromosomal region of the P. bryantii TC1-1 (Accetto \& Avguštin, 2001) showed that its hypothetical proteins share high amino acid sequence identity with Prevotella intermedia 17 proteins coded in loci PINA1518-1521, and that the gene order is conserved in this region. Preliminary genome sequence data of $P$. intermedia 17 were obtained from The Institute for Genomic Research web site (http://www. tigr.org). Survey of the flanking $P$. intermedia 17 genome regions revealed that a hypothetical non-specific nuclease lies only $4 \mathrm{kbp}$ away. Subsequently $4.9 \mathrm{~kb}$ of $P$. bryantii $\mathrm{B}_{1} 4$ genomic sequence, extending from the above-mentioned cloned region, was retrieved with inverse PCR and sequenced. The gene order between $P$. bryantii $\mathrm{B}_{1} 4$, TC1-1 and P. intermedia 17 was found to be conserved. Thus the sequence of a $P$. bryantii $\mathrm{B}_{1} 4 n u c B$, a homologue of the gene in locus PINA1511, was obtained.

Inverse PCR. Inverse PCR was performed in two rounds and essentially as described by Sambrook \& Russell (2001). In the first round, the P. bryantii $\mathrm{B}_{1} 4$ genomic DNA was cleaved with PstI,

Table 1. Primers used in the study

\begin{tabular}{|ll|}
\hline Name & \\
\hline inv1 & Sequence \\
inv2 & AGCATCTCGGTGCAACGTCATTC \\
inv3 & GTACCAGCTCCTTATACATTG \\
inv4 & GGTGAAGATACCAGTTACATC \\
pstnnucf & GCCGCTGCAGTTAAGTCAAGAGGGTACGTTC \\
pstnnucr & GCCGCTGCAGCTTCGTATGGTGTCTTGAGTC \\
pstnnucf1 & GCCGCTGCAGGCATATGCGGTCGGTCGTAC \\
pstnnucf2 & GCCGCTGCAGTAACTAAACTTCACTTATGCACAC \\
RTnucBf & TGGTTGCTTGCGGCAGTAG \\
RTnucBr & AGAAGCGGAAGACCCAGATGT \\
RT16Sf & AAATGTCCGGGCTCAACCT \\
RT16Sr & ACCGCTACACCACGAATTCC \\
kontrnnuc & GGTTAAGCCATGCGGGTATC \\
pstnucBrhis & GCCGCTGCAGTTATTAATGATGATGATGATGATGAGAACCCCCGTTAAGTTT- \\
& CCAGGCTCTTAG \\
\hline
\end{tabular}


religated and amplified with the primers inv1 and inv2. For the second inverse PCR, the $P$. bryantii $\mathrm{B}_{1} 4$ genomic DNA was fragmented using HindIII. After ligation, the neighbouring region to the one obtained with the first inverse PCR was amplified using the primers inv3 and inv4. Both inverse PCR products were cloned using the pBAD-TOPO TA kit (Invitrogen) and sequenced.

Expression of nucB in $\boldsymbol{P}$. bryantii TC1-1. The PCR-amplified $P$. bryantii $\mathrm{B}_{1} 4$ nucB gene variants were Pst $\mathrm{I}$ digested, ligated to the Pst $\mathrm{I}$ linearized and shrimp alkaline phosphatase-treated vector $\mathrm{pRH} 3$, and transferred to E. coli TOP10. The orientation of $n u c B$ in the resulting clones was determined by restriction analysis. The constructs having the same orientation as tetQ gene were isolated, verified by sequencing using the primer kontrnnuc, protected against the action of PbrTI restriction of $P$. bryantii TC1-1, and transferred to $P$. bryantii TC1-1 by electroporation (Accetto et al., 2005). The culture supernatants of the resulting $P$. bryantii TC1-1-derived strains, which were grown with $2.5 \mu \mathrm{g}$ tetracycline $\mathrm{ml}^{-1}$ unless stated otherwise, were assayed for nuclease activity either directly or were concentrated using Amicon Ultra4 10000 MWCO centrifugal filter devices from Millipore.

Nuclease SDS-PAGE assay. Nuclease detection in renatured SDSPAGE gels containing nucleic acids was performed essentially as described elsewhere (Rosenthal \& Lacks, 1977; Blank et al., 1982). Ten micrograms of salmon testes DNA (Fluka) and $40 \mu \mathrm{g} 16 \mathrm{~S}$ and $23 \mathrm{~S}$ rRNA from $E$. coli (Roche) per $\mathrm{ml}$ of the resolving gel were used.

\begin{abstract}
Isolation of the $6 \times$ His-tagged NucB from the P. bryantii TC1-1 carrying pRH3nuc3d. First, $150 \mathrm{ml}$ of culture supernatant was concentrated using Amicon Ultra4 10000 MWCO Millipore centrifugal filter devices. Buffer was then exchanged with Ni-NTA binding buffer from Ni-NTA buffer kit (Novagen) and NucB was purified under native conditions on Ni-NTA His bind resin (Novagen) as recommended by the manufacturer. Mercaptoethanol ( $5 \mathrm{mM})$ was added to all buffers used in purification. The elution fractions showing DNase activity were concentrated and the elution buffer was exchanged with buffer containing $20 \mathrm{mM}$ Tris $\mathrm{pH} 7.5$, $50 \mathrm{mM} \mathrm{NaCl}$ and $1 \mathrm{mM}$ mercaptoethanol. The activity of enzyme preparation was tested with $\lambda$ and pUC18 DNA as well as with $P$. bryantii TC1-1 RNA in the reactions, which contained $1 \mu \mathrm{g}$ nucleic acids, $5 \mathrm{mM} \mathrm{MgCl}_{2}$ as well as $20 \mathrm{mM}$ Tris $\mathrm{pH} 7.5,50 \mathrm{mM} \mathrm{NaCl}$ and $1 \mathrm{mM}$ mercaptoethanol. NucB cation requirement was tested in reactions where $\mathrm{MgCl}_{2}$ was replaced with $\mathrm{CaCl}_{2}, \mathrm{CoCl}_{2}$ or $\mathrm{MnCl}_{2}$.
\end{abstract}

RNA isolation. The total RNA was extracted from $8 \mathrm{ml} P$. bryantii TC1-1 cultures during exponential growth at $\mathrm{OD}_{600} 0.3$ using the Trizol reagent (Gibco-BRL), following the manufacturer's guidelines. Strains were grown in modified M330 medium unless stated otherwise.

Reverse transcription and real-time PCR. Reverse transcription was performed using the primers RT16sr and RTnucBr, which are specific for $P$. bryantii $16 \mathrm{~S}$ rRNA and $n u c B$ genes, respectively. The RNA was DNase I (Fermentas) treated and RevertAid H minus MMuLV reverse transcriptase (Fermentas) was used at $42{ }^{\circ} \mathrm{C}$. Control reactions lacking the reverse transcriptase were also performed. Portions of $1 \mu \mathrm{l}$ of $20 \mu \mathrm{l}$ reverse transcription reactions were used as templates for standard PCR, using the primer pairs RT16Sf RT16Sr and RTnucBf RTnucBr for amplification of $16 \mathrm{~S}$ rRNA and $n u c B$ gene fragment, respectively. The reactions yielded PCR products of 86 and $62 \mathrm{bp}$. The amount of $16 \mathrm{~S}$ rRNA and $n u c B$ cDNA was quantified with real-time PCR using the above-mentioned primers, Sybr Green PCR Master Mix from Applied Biosystems and the ABI PRISM 7900HT sequence detection system. Relative quantification of $n u c B$ cDNA was performed using the standard curve method, and the 16S rRNA amplicon was used as endogenous control for normalization. The samples were amplified in triplicate with the standard thermal cycling profile, and the results were analysed using SDS 2.2 software. RNA was isolated twice from the separate batches of modified M330 medium, and real-time measurement of each cDNA amount was repeated at least once. The amount of $n u c B$ mRNA present in the wild-type $P$. bryantii TC1-1 was used as a calibrator. Reverse transcription of RNA samples was repeated in order to check its reproducibility.

Western blot and immunodetection. Following the standard SDSPAGE, the proteins were transferred onto a PVDF membrane (BioRad) using the semi-dry Multiphor II NovaBlot apparatus (Pharmacia Biotech) with pieces of filter paper soaked in the cathode (25 mM Tris, $40 \mathrm{mM}$ glycine, $10 \%$, v/v, methanol, $\mathrm{pH} 9.4$ ) and anode buffers 1 and $2(0.3 \mathrm{M}$ Tris, $10 \%$ methanol, pH 10.4, and $25 \mathrm{mM}$ Tris, $10 \%$, v/v, methanol, $\mathrm{pH} \mathrm{10.4}$, respectively). The membrane was blocked with $5 \%(\mathrm{w} / \mathrm{v})$ skimmed milk powder (Merck) in TBST $(50 \mathrm{mM}$ Tris/ $\mathrm{HCl}, 150 \mathrm{mM} \mathrm{NaCl}, 0.1 \%$, v/v, Tween 20, pH 7.5), and immunodetection was performed using Antihis $_{6}$ mouse primary monoclonal antibody (Roche) and horseradish peroxidase-conjugated goat anti-mouse secondary antibody (Jackson Immunoresearch). The ECL Western blotting detection reagents (Amersham Biosciences) were used to generate chemiluminescence, which was recorded with the Chemigenius ${ }^{2}$ bio imaging system (Syngene).

\section{RESULTS}

\section{DNase and RNase activity of $P$. bryantii TC1-1 and $B_{1} 4$}

Using the nuclease SDS-PAGE assay, a DNase was observed in the concentrated culture supernatants and concentrated cell-wash extracts of M2-grown $P$. bryantii TC1-1 with the same apparent molecular mass as the $P$. bryantii $\mathrm{B}_{1} 4$ DNase. The latter was shown previously to have an apparent molecular mass of $45 \mathrm{kDa}$ (Accetto \& Avguštin, 2001). The RNase activity of the P. bryantii $\mathrm{B}_{1} 4$ cell-wash extracts was also assayed and RNase activity was observed at $45 \mathrm{kDa}$.

\section{Sequence analysis of $P$. bryantii $B_{1} 4$ nucB}

Its $33.5 \mathrm{kDa}$ predicted protein product belongs, according to PFAM, in the DNA/RNA non-specific endonuclease family, contains a predicted signal peptide and shares $49 \%$ amino acid identity with the protein coded in P. intermedia 17 locus PINA1511. Upstream of the $n u c B$ start codon, a $130 \mathrm{bp}$ sequence is located, containing a putative transcriptional terminator of the preceding ribosomal protein L31 gene, leaving only approximately $50 \mathrm{bp}$ for a putative promoter sequence. The length of the upstream region and putative terminator location is also conserved in $P$. intermedia 17. Promoter sequences typical for Bacteroides fragilis (Bayley et al., 2000) or P. bryantii (Peterka, 2002) were not found in this region. The aforementioned L31 ribosomal protein shares $90 \%$ amino acid sequence identity with its $P$. intermedia 17 counterpart. The $P$. bryantii TC1-1 nucB gene was subsequently successfully amplified with the primers pstnnucf and pstnnucr, which were designed on the basis of the P. bryantii $\mathrm{B}_{1} 4$ genomic 
sequence. It was found out that the genes are highly similar in the upstream region, as well as in structural part, with a total of only 21 nucleotide substitutions, 18 of them in the structural part (2\% difference), leading to $11(3.6 \%)$ amino acid differences between them.

\section{Expression of nucB in P. bryantii TC1-1}

Three $n u c B$ variants were produced from $P$. bryantii $\mathrm{B}_{1} 4$ genomic DNA by PCR, using the forward primers pstnnucf, pstnnucf1 and pstnnucf2, annealing at different positions in the $n u c B$ upstream region (Fig. 1), and the pstnnucr reverse primer. The PCR products were ligated to the shuttle vector $\mathrm{pRH} 3$, transferred first to E. coli TOP10 in order to check the orientation of the inserts, and then transferred to $P$. bryantii TC1-1. The recombinant plasmids containing 108,77 , and 16 bp of $n u c B$ upstream region in addition to the structural gene were named pRH3nuc3a, pRH3nuc3b and pRH3nuc3c, respectively. The DNase activity of $P$. bryantii TC1-1 containing pRH3nuc3a culture supernatant was slightly higher than control after growth for 1 day on conventional M2 medium for rumen bacteria. However, when this recombinant strain was grown on modified DSMZ medium M330, relatively strong nonspecific DNase activity was observed in the culture supernatants (Fig. 2). This activity resulted in cleavage of plasmid as well as $\lambda$ DNA, and was EDTA inhibited. When concentrated supernatants of modified M330-grown pRH3nuc3a bearing $P$. bryantii TC1-1 were analysed on SDS-PAGE nuclease gel, three zones of DNA degradation were observed: one coinciding with the already known major $P$. bryantii nuclease, and two other zones corresponding to the proteins of approximately 36 and $34 \mathrm{kDa}$. The same zones were present also in wild-type $P$. bryantii TC1-1. However, in the recombinant Strain TC1-1 bearing pRH3nuc3a, the intensity of DNA degradation was highest at $36 \mathrm{kDa}$, whereas the major activity of the wild-type strain was at $45 \mathrm{kDa}$ (Fig. 3). These additional DNA degradation zones were not seen when supernatants, concentrated supernatants, or cells of $P$. bryantii $\mathrm{B}_{1} 4$ grown in modified M330 were analysed. An additional $n u c B$ variant, carrying a $6 \times$ His-tag at its $C$ terminus, was amplified from $P$. bryantii $\mathrm{B}_{1} 4$ genomic DNA with the primers pstnnucf and pstnucBrhis, cloned as described above, yielding pRH3nuc3d, and transferred to P. bryantii TC1-1. When the concentrated culture supernatants of modified M330-grown $P$. bryantii TC1-1 carrying a $6 \times$ His-tag variant of $n u c B$ were analysed by Western

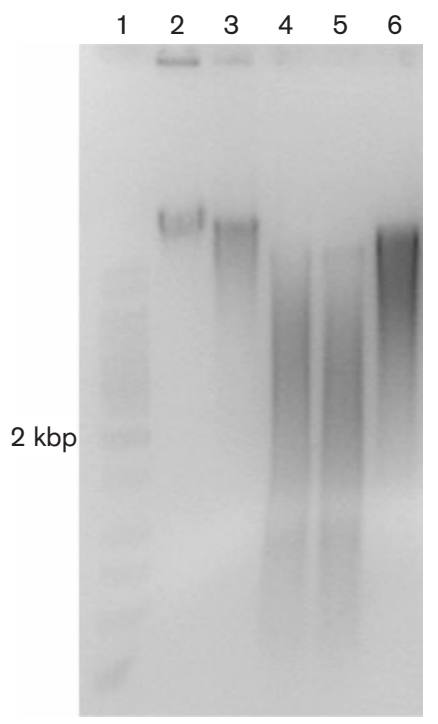

Fig. 2. Culture supernatant DNase activity of $P$. bryantii TC1-1 recombinant strains grown in M330 medium. Bacteriophage $\lambda$ was used as the substrate. Lane 1, $1 \mathrm{~kb}$ standard (Fermentas); lane 2, bacteriophage $\lambda \mathrm{DNA}$; lane 3, TC1-1 wild-type strain; lanes 4, 5 and 6 , strain $\mathrm{TC} 1-1$ harbouring $\mathrm{pRH} 3$ nuc $3 \mathrm{a}, \mathrm{pRH} 3$ nuc $3 \mathrm{~b}$ and pRH3nuc3c, respectively.

blotting, using anti $6 \times$ His antibodies, two chemiluminiscent bands were observed at $37 \mathrm{kDa}$ and $42 \mathrm{kDa}$ (Fig. 4).

\section{Isolation of NucB from P. bryantii TC1-1 carrying pRH3nuc3d grown in M330}

$6 \times$ His-tagged NucB was purified from the culture supernatant on Ni-NTA resin. The DNase-active elution fractions contained two protein bands when analysed by SDS-PAGE, with the molecular masses coinciding with those observed in Western blots. Purified NucB degraded $\lambda$ and pUC18 DNA, as well as RNA, and the DNase activity was inhibited by $20 \mathrm{mM}$ EDTA. DNase activity was comparable when $\mathrm{MgCl}_{2}$ was replaced with $\mathrm{CoCl}_{2}$ or $\mathrm{MnCl}_{2}$. Activity was not observed when $\mathrm{CaCl}_{2}$ was used or when no divalent cations were added to the reaction mixtures. The addition of $20 \mathrm{mM}$ EDTA did not inhibit the RNase activity significantly, and $\mathrm{MgCl}_{2}$ was also not required for activity.
TAAATATATCCTTTATAAGTATATATTAAGTCAAGAGGGTACGTTCGAGC -130 108 pstnnuc GTAGTTGCATATGCGGTCGgTCGTACCCTTTATCGTTTTAAACGAAATT -77 pstnnucf1

TCAATAGGTAATTCTATATAACTAAACTTCACTTATGCACACAATTAAAT -16 pstnnucf2

CTTTATTTTTAGCCATGGGCGTATTAGCTCTGGTTGCTTGCGGCAGTAG
Fig. 1. The nucB upstream sequence. Primer annealing sites are shown in bold, the putative transcription terminator is shown in italics, and the nucB and ribosomal protein L31 gene start and stop codons, respectively, are underlined. 


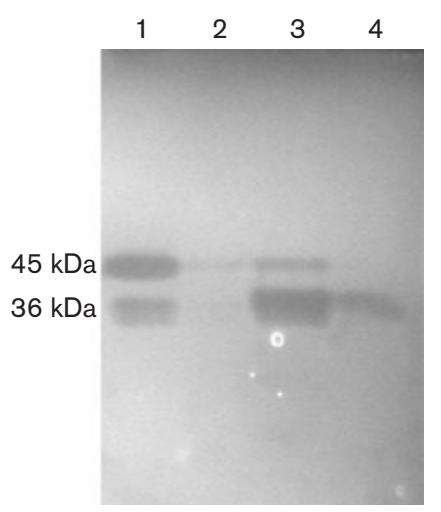

Fig. 3. Concentrated culture supernatant DNase activity of $P$. bryantii TC1-1 harbouring nucB in $\mathrm{pRH} 3$ nuc3a analysed on renatured SDS-PAGE gel containing DNA. Lanes 1 and 2, TC1-1 wild-type strain with and without mercaptoethanol in the loading buffer; lanes 3 and 4, strain TC1-1 containing pRH3nuc3a with and without mercaptoethanol in the loading buffer.

\section{Analysis of the nucB upstream region}

The analysis of the DNase activity of P. bryantii TC1-1 recombinant strains described above, grown in modified M330 medium, showed that $P$. bryantii TC1-1 containing pRH3nuc3b ( $n u c B$ beginning at position -77) had slightly higher activity than the -108 variant (pRH3nuc3a). The strain harbouring pRH3nuc3c, however, which contained only 16 bp of the upstream region, had markedly decreased nuclease activity, which was only slightly higher than in the wild-type strain (Fig. 2).

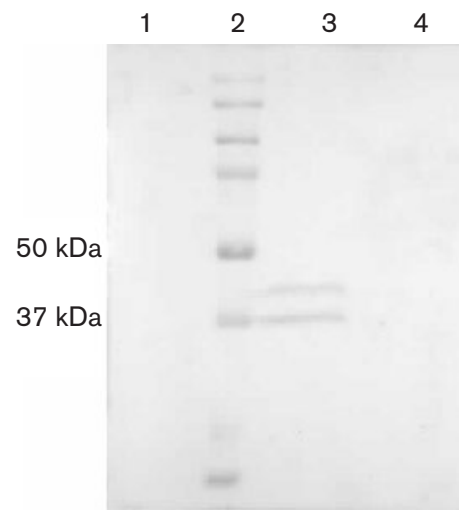

Fig. 4. Western blot analysis of concentrated culture supernatants of the $P$. bryantii strain TC1-1, harbouring pRH3nuc3d coding for His-tagged NucB. Lane 1, TC1-1 wild-type strain; lane 2. Precision plus protein standard (Bio-Rad); lane 3, TC1-1 harbouring $\mathrm{pRH} 3 n u c 3 d$, tetracycline added; lane 4, TC1-1 harbouring $\mathrm{pRH} 3 n u c 3 d$, tetracycline omitted.

\section{Quantification of nucB mRNA in P. bryantii strains harbouring pRH3nuc3a, pRH3nuc3b and pRH3nuc3c}

The amount of $n u c B$ mRNA was quantified with two-step real-time RT-PCR. When tetracycline was omitted from the modified M330 medium, the amount of $n u c B$ mRNA decreased approximately three- to fivefold in recombinant strains (pRH3nuc $3 \mathrm{a}, 1.7 \pm 0.06$ vs $5.6 \pm 1.8$; pRH3nuc $3 \mathrm{~b}$, $1.6 \pm 0.4$ vs $8.1 \pm 2.8 ;$ pRH3nuc 3 c, $2.4 \pm 1.0$ vs $8.8 \pm 2.1$; means $\pm S D$ of at least four measurements), but stayed above the control level, i.e. the amount in the wild-type strain TC1-1. Supernatants of cultures grown without tetracycline were also checked for DNase activity, which decreased to levels comparable to wild-type activity (not shown). It was not possible to detect $\mathrm{NucB}$ on Western blots when tetracycline was omitted from the growth medium of pRH3nuc3d containing $P$. bryantii TC1-1 (Fig. 4). Plasmids were present in the strains also in the absence of tetracycline, and the plasmid yield was unchanged. The amount of $n u c B$ mRNA in P. bryantii TC1-1 pRH3nuc3b, grown on modified M330 medium or on M2 medium, was comparable, the latter being $7.2 \pm 1.8$ times higher than $n u c B$ mRNA of $P$. bryantii TC1-1 wildtype grown in modified M330 medium.

\section{RT-PCR analysis of nucB mRNA transcript}

In order to determine whether the transcription of $n u c B$ mRNA in P. bryantii TC1-1 harbouring one of the pRH3nuc3 plasmids started from the tetQ promoter, an RT-PCR experiment was performed with the primers $\mathrm{RTnucBr}$, which was used for reverse transcription and PCR, and kontrnnuc, the later annealing 109 bases upstream of the tetQ stop codon in pRH3. This primer pair should produce an RT-PCR product only when $n u c B$ mRNA is part of a larger mRNA transcript starting with tetQ, i.e. 522, 491 and $430 \mathrm{bp}$ products from $n u c B$ mRNA of P. bryantii TC1-1 harbouring pRH3nuc3a, pRH3nuc3b and $\mathrm{pRH} 3$ nuc $3 \mathrm{c}$, respectively. The RT-PCR product of expected size was in fact observed for all $n u c B$ variants carried on plasmids in $P$. bryantii TC1-1 regardless of whether tetracycline was added to the growth medium or not.

\section{DISCUSSION}

We recently developed a reasonably fast and efficient gene introduction protocol for $P$. bryantii TC1-1 involving methylase plasmid protection and electroporation (Accetto et al., 2005), which was successfully used in this study for the delivery of plasmids containing nuclease genes. The shuttle vector used was pRH3 (Daniel et al., 1995). It is composed of already sequenced $3.2 \mathrm{~kb}$ cryptic plasmid pRRI2, isolated from Prevotella sp. 223/M2/7 (Mercer et al., 2001), the tet $Q$ gene from Bacteroides plasmid pNFD13-2 and E. coli cloning vector pBluescript SK+ (Fig. 5). $P$. bryantii TC1-1 possesses a nuclease with the same apparent 


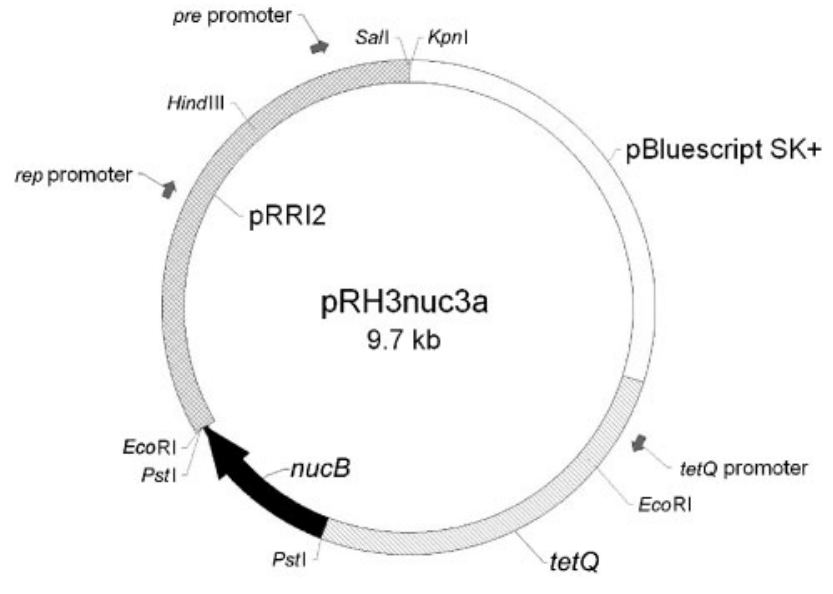

Fig. 5. Map of the shuttle vector $\mathrm{pRH}$. nucB was inserted into the Pstl site downstream of tetQ and in the same orientation. Location and orientation of Prevotella/Bacteroides promoters is also shown.

molecular mass as the previously described $45 \mathrm{kDa}$ major nuclease of $P$. bryantii $\mathrm{B}_{1} 4$ (Accetto \& Avguštin 2001). However, the nuclease activity of TC1-1 is far weaker than that of other P. bryantii strains, thus making it a suitable recipient for nuclease genes. Two additional zones of DNA degradation, corresponding to proteins with molecular masses of approx. 34 and $36 \mathrm{kDa}$, were discovered when $P$. bryantii TC1-1 was grown in modified M330 medium.

Into this background a gene from $P$. bryantii $\mathrm{B}_{1} 4$ strain, named $n u c B$, putatively coding for a $33.5 \mathrm{kDa}$ non-specific nuclease, was introduced on a pRH3 shuttle vector. $n u c B$ was cloned into the PstI site of pRH3, downstream and in the same orientation as the tetQ gene, thus placing it in a putative transcriptional fusion with tetQ (Fig. 5). Clearly increased DNase activity was observed in the supernatants of the recombinant TC1-1 strain. The amount of the $36 \mathrm{kDa}$ DNase, as judged from renatured DNase SDS-PAGE gels, was increased too. The DNase activity was only present to a clearly higher degree when the recombinant strain $P$. bryantii TC1-1 was grown in modified M330 medium; the increase in the activity was much lower when the strain was grown in M2 medium. The Western blot analysis confirmed that Histagged NucB is actually expressed from the plasmid, and migrates as a $37 \mathrm{kDa}$ protein; however, a second, $42 \mathrm{kDa}$ protein, was also detected. The latter could represent posttranslationally modified NucB, possibly by glycosylation, an inactive precursor, or the product of an aberrant start/stop codon. His-tagged NucB was also purified from P. bryantii TC1-1 culture supernatants and was shown to be an endonuclease that degrades DNA as well as RNA. It appears therefore that $n u c B$ actually codes for a minor $P$. bryantii non-specific nuclease.

The experiment with a truncated $n u c B$ upstream region suggests that the region between 77 and $16 \mathrm{bp}$ upstream of the translational start site is required for $n u c B$ upregulation in modified M330 medium. Unexpectedly, strain TC1-1 bearing the $n u c B$ variant with only $16 \mathrm{bp}$ of the $n u c B$ upstream region and having only slightly increased DNase activity contained at least the same amount of $n u c B$ mRNA as the strains with other two $n u c B$ variants. This, together with the observation that the $n u c B$ upstream region lacks Bacteroides -7 and -33 promoter sequences, led us to consider that the $n u c B$ upstream region does not actually function as a promoter. It was therefore possible that $n u c B$ was transcribed as part of a larger mRNA starting at the tetQ promoter around $2.5 \mathrm{kbp}$ upstream (Fig. 5). An RTPCR experiment with primers flanking the presumed junction between $n u c B$ and tetQ mRNA confirmed that a single tetQ- $n u c B$ mRNA transcript exists. pRH3 is stable in $P$. bryantii TC1-1 in the absence of tetracycline (Accetto et al., 2005) and when tetracycline was omitted from the growth medium, the amount of $n u c B$ mRNA fell, which is in accordance with findings in Bacteroides thetaiotaomicron (Wang et al., 2004). Along with the drop of $n u c B$ mRNA, the DNase activity in the supernatants fell and His-tagged $\mathrm{NucB}$ was no longer detected on Western blots. All these observations argue that the $n u c B$ upstream region exerts its influence on the $n u c B$ expression at the translation level. Consistent with this is the observation that P. bryantii TC11 harbouring pRH3nuc3b contains roughly the same relative amount of $n u c B$ mRNA when grown either on M2 or M330 medium, but has markedly lower DNase activity in the supernatants when grown in M2 medium.

The genome of $P$. intermedia 17 contains, apart from a gene homologous to $n u c B$, another gene in locus PIN0092, coding for a $42 \mathrm{kDa}$ protein, which belongs, like NucB, to the DNA/RNA non-specific nuclease protein family, representing the major nucleases in many bacteria. Given the suspected gene order conservation between $P$. bryantii $\mathrm{B}_{1} 4$ and $P$. intermedia 17 , and their similar genome sizes (Peterka, 2002), P. bryantii may also harbour a PIN0092 homologue whose product could actually be the major nuclease. Knockout and analysis of this gene would most likely result in increase of electrotransformation frequency of $P$. bryantii strains with $\mathrm{pRH} 3$ and shed light on the function of $P$. bryantii DNases.

The gene introduction system for P. bryantii TC1-1 based on the vector $\mathrm{pRH} 3$ proved reliable. The possibility of regulating the transcription of a foreign gene cloned into the unique PstI and XbaI sites of $\mathrm{pRH} 3$ via the tetracycline concentration, together with the stability of the plasmid in $P$. bryantii TC1-1 in the absence of tetracycline, enhances the usability of $\mathrm{pRH} 3$ beyond mere gene delivery. The $n u c B$ expression in P. bryantii TC1-1 is to our knowledge the first instance of successful expression of any gene from artificially constructed plasmid vectors apart from plasmid replication and tetracycline resistance genes in genus Prevotella.

\section{ACKNOWLEDGEMENTS}

This work was supported by the Slovenian Research Agency (P4-0097 (C)). 


\section{REFERENCES}

Accetto, T. \& Avguštin, G. (2001). Non-specific DNases from the rumen bacterium Prevotella bryantii. Folia Microbiol (Praha) 46, 33-35.

Accetto, T., Peterka, M. \& Avguštin, G. (2005). Type II restriction modification systems of Prevotella bryantii TC1-1 and Prevotella ruminicola 23 strains and their effect on the efficiency of DNA introduction via electroporation. FEMS Microbiol Lett 247, 177-183.

Altschul, S. F., Madden, T. L., Schäffer, A. A., Zhang, J., Zhang, Z., Miller, W. \& Lipman, D. J. (1997). Gapped BLAST and PSI-BLAST: a new generation of protein database search programs. Nucleic Acids Res 25, 3389-3402.

Avguštin, G., Wallace, R. J. \& Flint, H. J. (1997). Phenotypic diversity among ruminal isolates of Prevotella ruminicola: proposal of Prevotella brevis sp. nov., Prevotella bryantii sp. nov., and Prevotella albensis sp. nov. and redefinition of Prevotella ruminicola. Int J Syst Bacteriol 47, 284-288.

Avguštin, G., Ramšak, A. \& Peterka, M. (2001). Systematics and evolution of ruminal species of the genus Prevotella. Folia Microbiol (Praha) 46, 40-44.

Bateman, A., Coin, L., Durbin, R., Finn, R. D., Hollich, V., GriffithsJones, S., Khanna, A., Marshall, M., Moxon, S. \& other authors (2004). The Pfam protein families database. Nucleic Acids Res 32 (Database issue), D138-D141.

Bayley, D. P., Rocha, E. R. \& Smith, C. J. (2000). Analysis of cepA and other Bacteroides fragilis genes reveals a unique promoter structure. FEMS Microbiol Lett 193, 149-154.

Bendjennat, M., Blanchard, A., Loutfi, M., Montagnier, L. \& Bahraoui, E. (1999). Role of Mycoplasma penetrans endonuclease $\mathrm{P} 40$ as a potential pathogenic determinant. Infect Immun 67, 4456-4462.

Bendtsen, J. D., Nielsen, H., von Heijne, G. \& Brunak, S. (2004). Improved prediction of signal peptides: SignalP 3.0. J Mol Biol 340, 783-795.

Benedik, M. J. \& Strych, U. (1998). Serratia marcescens and its extracellular nuclease. FEMS Microbiol Lett 165, 1-13.

Blank, A., Sugiyama, R. H. \& Dekker, C. A. (1982). Activity staining of nucleolytic enzymes after sodium dodecyl sulfate-polyacrylamide gel electrophoresis: use of aqueous isopropanol to remove detergents from gels. Anal Biochem 120, 267-275.

Brook, I. (2004). Microbiology and management of peritonsillar, retropharyngeal, and parapharyngeal abscesses. J Oral Maxillofac Surg 62, 1545-1550.

Bryant, M. P., Small, N., Bouma, C. \& Chu, H. (1958). Bacteroides ruminicola $\mathrm{n}$. sp. and Succinimonas amylolytica, the new genus and species. J Bacteriol 76, 15-23.

Daniel, A. S., Martin, J., Vanat, I., Whitehead, T. R. \& Flint, H. J. (1995). Expression of a cloned cellulase xylanase gene from Prevotella ruminicola in Bacteroides vulgatus, Bacteroides uniformis and Prevotella ruminicola. J Appl Bacteriol 79, 417-424.

Dubnau, D. (1999). DNA uptake in bacteria. Annu Rev Microbiol 53, 217-244.

Duncan, W. J., Persson, G. R., Sims, T. J., Braham, P., Pack, A. R. C. \& Page, R. C. (2003). Ovine periodontitis as a potential model for periodontal studies. J Clin Periodontol 30, 63-72.

Eckburg, P. B., Bik, E. M., Bernstein, C. N., Purdom, E., Dethlefsen, L., Sargent, M., Gill, S. R., Nelson, K. E. \& Relman, D. A. (2005). Diversity of the human intestinal microbial flora. Science 308, 1635-1638.

Edwards, J. E., McEwan, N. R., Travis, A. J. \& Wallace, R. J. (2004). 16S rDNA library-based analysis of ruminal bacterial diversity. Antonie Van Leeuwenhoek 86, 263-281.
Enwonwu, C. O., Falker, W. A., Jr \& Phillips, R. S. (2006). Noma (cancrum oris). Lancet 368, 147-156.

Focareta, T. \& Manning, P. A. (1991). Distinguishing between the extracellular DNases of Vibrio cholerae and development of a transformation system. Mol Microbiol 5, 2547-2555.

Gardner, R. G., Russell, J. B., Wilson, D. B., Wang, G. R. \& Shoemaker, N. B. (1996). Use of a modified Bacteroides-Prevotella shuttle vector to transfer a reconstructed $\beta$-1,4-D-endoglucanase gene into Bacteroides uniformis and Prevotella ruminicola $\mathrm{B}_{1} 4$. Appl Environ Microbiol 62, 196-202.

Hobson, P. N. (1969). Rumen bacteria. Methods Microbiol 3B, 133-149.

Jarvill-Taylor, K. J., VanDyk, C. \& Minion, F. C. (1999). Cloning of mпиA, a membrane nuclease gene of Mycoplasma pulmonis, and analysis of its expression in Escherichia coli. J Bacteriol 181, 1853-1860.

Kolenbrander, P. E., Anderson, R. N., Blehert, D. S., Egland, P. G., Foster, J. S. \& Palmer, R. J., Jr (2002). Communication among oral bacteria. Microbiol Mol Biol Rev 66, 486-505.

Leser, T. D., Amenuvor, J. Z., Jensen, T. K., Lindecrona, R. H., Boye, M. \& Møller, K. (2002). Culture-independent analysis of gut bacteria: the pig gastrointestinal tract microbiota revisited. Appl Environ Microbiol 68, 673-690.

Martin, F. E., Nadkarni, M. A., Jacques, N. A. \& Hunter, N. (2002). Quantitative microbiological study of human carious dentine by culture and real-time PCR: association of anaerobes with histopathological changes in chronic pulpitis. J Clin Microbiol 40, 1698-1704.

Mercer, D. K., Patel, S. \& Flint, H. J. (2001). Sequence analysis of the plasmid pRRI2 from the rumen bacterium Prevotella ruminicola 223/ M2/7 and the use of pRRI in Prevotella/Bacteroides shuttle vectors. Plasmid 45, 227-232.

Miyazaki, K., Miyamoto, H., Mercer, D. K., Hirase, T., Martin, J. C., Kojima, Y. \& Flint, H. J. (2003). Involvement of the multidomain regulatory protein $\mathrm{XynR}$ in positive control of xylanase gene expression in the ruminal anaerobe Prevotella bryantii $\mathrm{B}_{1} 4 \mathrm{~J}$ Bacteriol 185, 2219-2226.

Paster, B. J., Boches, S. H., Galvin, J. L., Ericson, R. E., Lau, C. N., Levanos, V. A., Sahasrabudhe, A. \& Dewhirst, F. E. (2001). Bacterial diversity in human subgingival plaque. J Bacteriol 183, 3770-3783.

Peterka, M. (2002). Characterization of rrn loci from bacterial species Prevotella ruminicola and Prevotella bryantii. $\mathrm{PhD}$ thesis, University of Ljubljana, Ljubljana, Slovenia.

Provvedi, R., Chen, I. \& Dubnau, D. (2001). NucA is required for DNA cleavage during transformation of Bacillus subtilis. Mol Microbiol 40, 634-644.

Rangarajan, E. S. \& Shankar, V. (2001). Sugar non-specific endonucleases. FEMS Microbiol Rev 25, 583-613.

Rosenthal, A. L. \& Lacks, S. A. (1977). Nuclease detection in SDSpolyacrylamide gel electrophoresis. Anal Biochem 80, 76-90.

Sambrook, J. \& Russel, D. W. (2001). Molecular Cloning: a Laboratory Manual, 3rd edn. Cold Spring Harbor, NY: Cold Spring Harbor Laboratory.

Shoemaker, N. B., Anderson, K. L., Smithson, S. L., Wang, G. R. \& Salyers, A. A. (1991). Conjugal transfer of a shuttle vector from the human colonic anaerobe Bacteroides uniformis to the ruminal anaerobe Prevotella (Bacteroides) ruminicola $\mathrm{B}_{1} 4$. Appl Environ Microbiol 57, 2114-2120.

Takahashi, I., Hayano, D., Asayama, M., Masahiro, F., Watahiki, M. \& Shirai, M. (1996). Restriction barrier composed of an extracellular nuclease and restriction endonuclease in the unicellular cyanobacterium Microcystis sp. FEMS Microbiol Lett 145, 107-111. 
Van Gylswyk, N. O. (1990). Enumeration and presumptive identification of some functional groups of bacteria in the rumen of dairy cows fed grass silage-based diets. FEMS Microbiol Lett 73, 243-261.

Vingadassalom, D., Kolb, A., Mayer, C., Rybkine, T., Collatz, E. \& Podglajen, I. (2005). An unusual primary sigma factor in the Bacteroidetes phylum. Mol Microbiol 56, 888-902.

Walker, N. D., McEwan, N. R. \& Wallace, R. J. (2003). Cloning and functional expression of dipeptidyl peptidase IV from the ruminal bacterium Prevotella albensis M384. Microbiology 149, 2227-2234.
Wang, Y., Shoemaker, N. B. \& Salyers, A. A. (2004). Regulation of a Bacteroides operon that controls excision and transfer of the conjugative transposon CTnDOT. J Bacteriol 186, 2548-2557.

Wu, S. I., Lo, S. K., Shao, C. P., Tsai, H. W. \& Hor, L. I. (2001). Cloning and characterization of a periplasmic nuclease of Vibrio vulnificus and its role in preventing uptake of foreign DNA. Appl Environ Microbiol 67, 82-89.

Edited by: H. J. Strobel 